THEORY AND METHODS

\title{
Accuracy of adults' recall of childhood social class: findings from the Aberdeen children of the 1950s study
}

\author{
G David Batty, Debbie A Lawlor, Sally Macintyre, Heather Clark, David A Leon
}

J Epidemiol Community Health 2005;59:898-903. doi: 10.1136/jech.2004.030932

See end of article for authors' affiliations

\section{Correspondence to:}

Dr G D Batty, MRC Social and Public Health Sciences Unit, University of

Glasgow, Glasgow G12 8RZ, UK; david-b@msoc. mrc.gla.ac.uk

Accepted for publication 19 April 2005
Background: Although adult reported childhood socioeconomic position has been related to health outcomes in many studies, little is known about the validity of such distantly recalled information. This study evaluated the validity of adults' reports of childhood paternal social class.

Methods: Data are drawn from the Aberdeen children of the 1950s study, a cohort of 12150 people born in Aberdeen (Scotland) who took part in a school based survey in 1962. In this survey, two indices of early life socioeconomic position were collected: occupational social class at birth (abstracted from maternity records) and occupational social class in childhood (reported during the 1962 survey by the study participants). Between 2000 and 2003, a questionnaire was mailed to traced middle aged cohort members in which inquiries were made about their fathers' occupation when they were aged 12 years. The level of agreement between these reports and prospectively collected data on occupational social class was assessed.

Results: In total, 7183 (63.7\%) persons responded to the mid-life questionnaire. Agreement was moderate between social class of father recalled in adulthood and that measured in early life ( $\kappa$ statistics were 0.47 for social class measured at birth, and 0.56 for social class reported by the child). The relation of occupational social class to birth weight and childhood intelligence was in the expected directions, although weaker for adults' reports in comparison with prospectively gathered data.

Conclusions: In studies of adult disease aetiology, associations between childhood social class based on adult recall of parental occupation and health outcomes are likely to underestimate real effects. in the past decade there has been a re-emergence of interest in the early life origins of adult disease, particularly coronary heart disease (CHD). ${ }^{1-4}$ One of the most commonly examined social determinants is childhood socioeconomic position, ${ }^{5}$ typically indexed by the occupational social class of the father during the study participants' early life. An association with later life CHD events ${ }^{5}{ }^{6}$ and its risk factors $^{7-9}$ has been reported, such that the most unfavourable levels are apparent in adults from the most disadvantaged socioeconomic backgrounds.

Given the scarcity of prospective studies that offer extended follow up of children into later life, out of necessity most investigators examining the aetiological role of childhood social conditions have done so in cohorts of middle aged persons where this information is recalled from as much as six decades earlier. ${ }^{8-12}$ This practice raises important concerns about the accuracy of such data, not only when it is the exposure of interest but also when assessing its potential confounding effects. ${ }^{13}{ }^{14}$

While investigators have reported on the accuracy of children's or young persons' contemporaneous recall of their parents' occupation ${ }^{15} 16$ and adults' reports of their own occupational history up to 40 years in the past, ${ }^{17}$ we are aware of only two studies that have attempted to examine the accuracy of adults' recall of their childhood social class. In one, ${ }^{18}$ the degree of corroboration between adult twins' reports of parental occupation was assessed but no comparison was made with independently collected information in childhood such as that available in historical records. In another, ${ }^{19}$ although levels of agreement between archived records and adult self report appeared high, the analyses were based on less than 60 subjects. A further shortcoming of these studies, and one that often applies to validation studies in general, is that no estimate was provided of the probable effects of any misclassification.
The children of the 1950s study is a large cohort of men and women who participated in a school based survey in Aberdeen, Scotland in 1962. Data on childhood socioeconomic position and other characteristics were collected at the time of their birth (mother's reports of husband's occupation; birth weight) and during the school survey (study participants' report of father's occupation; psychometric intelligence)..$^{20}$ Recently, a questionnaire was mailed to surviving cohort members, now middle aged, in which inquiries were made regarding the respondents' childhood social circumstances, including their father's occupation.

We are therefore able to: (1) quantify the accuracy of distantly recalled occupational social class by relating paternal social class as ascertained from both historical records (at birth) and children's reports (during original survey), on the one hand, with childhood social class reported in middle age, on the other; (2) assess the likely effect of any misclassification by relating both child and adult recalled occupational social class to outcome variables known to be associated with contemporaneously gathered data on childhood social circumstances: birth weight ${ }^{21} 22$ and psychometric intelligence. ${ }^{23}$

\section{METHODS}

\section{Study participants}

The Aberdeen children of the 1950s study is a cohort of 12150 children born in Aberdeen, Scotland, between 1950 and 1956 who took part in a school based survey beginning in 1962. ${ }^{20} 24$ During this time, comprehensive information was also abstracted from the Aberdeen Maternity and Neonatal Databank (AMND) about the course of their mother's pregnancy and the children's physical characteristics at birth. ${ }^{20}$ In 1999 this study was revitalised with surviving cohort members traced and mailed a questionnaire between 
Table 1 Study participants with occupational social class data in childhood and adulthood

\begin{tabular}{|c|c|c|c|c|}
\hline Year of data collection & Reference period & Subjects with data* & Manual† & Non-manual \\
\hline $\begin{array}{l}\text { Infancy (1950-56) } \\
\text { Childhood (1962) } \\
\text { Adulthood (2000-03) }\end{array}$ & $\begin{array}{l}\text { Birth } \\
6-12 \text { years } \\
12 \text { year }\end{array}$ & $\begin{array}{r}11469(94.4) \\
11233(92.5) \\
6594(54.3)\end{array}$ & $\begin{array}{l}8971(78.2) \\
8127(72.4) \\
4742(71.9)\end{array}$ & $\begin{array}{l}2498(21.8) \\
3106(27.7) \\
1852(28.1)\end{array}$ \\
\hline
\end{tabular}

*Results are number (\%). †Occupational social class dichotomised into manual (IIIM, IV, and V) and non-manual (I, II, IIINM) groups.

2000 and 2003 regarding health and health related factors. ${ }^{20} 26$

\section{Prospective assessment of early life social class}

Occupational social class of the study participant's father was assessed at two time points in early life: birth and childhood. Social class at birth was based on the occupation of the participant's father, reported by the study participant's mother, and recorded in the AMND. The AMND records, established and maintained for analytical purposes by a team of experienced researchers, hold research-standard information. $^{20}{ }^{27}$ At the time of the school based survey (1962), the father's occupation was reported by each child. Studies of the accuracy of occupational social class reported simultaneously by child and parent suggest a high level of agreement. ${ }^{15} 16$ Data from both time points were classified into six categories according to schema resembling the 1950 registrar general's revision ${ }^{28}$ : I-professional; II-managerial; IIINM-nonmanual, skilled non-manual; IIIM-manual, skilled manual; IV-manual, semi-skilled; and V-unskilled manual. As this is an occupational classification, data were not coded for children whose fathers were unemployed at either birth and/ or when they were surveyed at school.

\section{Retrospective assessment of early life social class}

Using the procedures of the NHS Central Register, over 98\% $(n=12015)$ of the children of the 1950s cohort have been successfully traced. Between 2000 and 2003 we attempted to mail a questionnaire to 11283 surviving study participants aged between about 44 and 52 years. In total, 7183 (63.7\%) responded. Responders were more likely to be female, ${ }^{20}$ have higher psychometric intelligence scores as children, ${ }^{26}$ and to come from more affluent backgrounds in childhood.

Questionnaire respondents were asked to consider the period when they were 12 years of age. This epoch was chosen because it was close to the midpoint of childhood, and also the time at which most study participants would have transferred from junior to senior school, so representing a memorable period in their lives. Participants provided information on their father's occupation by replying to inquiries regarding his job title and job description that included an item with pre-defined categories: manager or foreman/supervisor; an employee (other than manager; foreman/supervisor); self employed with employees; self employed/freelance without employees. These data were converted to a standard occupational classification and then the registrar general's 1961 schema $^{29}$ (the earliest revision available electronically) using CASOC software. ${ }^{30}$

\section{Assessment of other characteristics}

During the study period in the early 1960s, educational authorities in Scotland routinely measured intelligence as a means of determining the secondary school destination of each child (that is, junior or senior secondary). Tests of psychometric intelligence were given to school children at 7 , 9 , and 11 years of age, and these scores were extracted from school records at the time of the schools based survey. ${ }^{20}$ In our analyses we used the test results at age 7 as our measure of childhood psychometric intelligence as this provides an indication of mental ability largely unaffected by formal education. The tests used were the Moray House picture intelligence tests number 1 or 2 , which was given within six months of the study participants' 7 th birthday. ${ }^{20}$ The test is based on line drawings and examines a child's perception and understanding of pictorial differences. Although, to our knowledge, the Moray House test has not been validated against other childhood IQ tests, in this cohort it shows the expected associations with early life social conditions, ${ }^{20}$ fetal growth, ${ }^{31}$ and adult mortality experience. ${ }^{26}$ Data on birth weight, measured directly by midwives, were abstracted from the AMND. Again, in this population, birth weight shows the expected inverse relations with childhood visual acuity ${ }^{32}$ and adult cardiovascular disease risk. ${ }^{33}$

\section{Statistical analyses}

Analyses were conducted for the full range of social class categories. The agreement between each measure of occupational social class was estimated visually by presenting cross tabulations and statistically by computing percentage agreement and weighted $\kappa$ statistics. Weighted $\kappa$ statistics were used to account for the greater disagreement between categories that are further apart than those that are close together on an ordinal scale. ${ }^{34}$ Linear weights were calculated as $w_{i}=1-(i / 5)$, where $w_{i}$ is the weight given for a distance of

Table 2 Agreement between social class data based on birth records and adult reports

\begin{tabular}{|c|c|c|c|c|c|c|c|c|}
\hline & & \multicolumn{6}{|c|}{ Birth records } & \multirow[b]{2}{*}{ Total } \\
\hline & & I & II & III NM† & III $M \ddagger$ & IV & V & \\
\hline \multirow[t]{7}{*}{ Adult reports } & 1 & 136 & 69 & 10 & 55 & 3 & 2 & 275 \\
\hline & $\|$ & 41 & 340 & 214 & 271 & 41 & 34 & 941 \\
\hline & IIINM & 6 & 82 & 280 & 132 & 40 & 29 & 569 \\
\hline & IIIM & 6 & 53 & 181 & 2099 & 401 & 380 & 3120 \\
\hline & IV & 2 & 24 & 125 & 357 & 348 & 265 & 1121 \\
\hline & V & 0 & 1 & 9 & 60 & 53 & 215 & 338 \\
\hline & Total & 191 & 569 & 819 & 2974 & 886 & 925 & $6364^{*}$ \\
\hline
\end{tabular}

*Level agreement $=54.0 \%$; weighted $\kappa$ statistic $=0.47, \mathrm{p}<0.001$. †non-manual; tmanual. Occupational social class was categorised as follows: I (highest) professional; II-managerial; IIINM-non-manual, skilled non-manual; IIIM-manual, skilled manual; IV-manual, semi-skilled; and V (lowest)-unskilled manual. 
Table 3 Agreement between social class data based on childhood reports and adult reports

\begin{tabular}{|c|c|c|c|c|c|c|c|c|}
\hline & & \multicolumn{6}{|c|}{ Childhood reports } & \multirow[b]{2}{*}{ Total } \\
\hline & & I & II & III NM† & III $M \ddagger$ & IV & V & \\
\hline \multirow[t]{7}{*}{ Adult reports } & 1 & 165 & 60 & 9 & 44 & 5 & 1 & 284 \\
\hline & $\|$ & 57 & 511 & 186 & 153 & 28 & 28 & 963 \\
\hline & IIINM & 14 & 96 & 338 & 63 & 42 & 8 & 561 \\
\hline & IIIM & 3 & 131 & 168 & 2241 & 328 & 232 & 3103 \\
\hline & IV & 2 & 38 & 179 & 282 & 419 & 163 & 1083 \\
\hline & V & 1 & 0 & 8 & 53 & 58 & 206 & 326 \\
\hline & Total & 242 & 836 & 888 & 2836 & 880 & 638 & 6320 * \\
\hline
\end{tabular}

${ }^{*}$ Level agreement $=61.4 \%$; weighted $\kappa$ statistic $=0.56, p<0.001 ;$ tnon-manual; $\ddagger$ manual. Occupational social class was categorised as follows: I (highest) professional; II-managerial; IIINM-non-manual, skilled non-manual; IIIM-manual, skilled manual; IV-manual, semi-skilled; and V (lowest)-unskilled manual.

$i$ categories between the two measurements of occupational social class. Using the original six occupational categories, the weights applied were therefore $1,0.8,0.6,0.4,0.2,0$ when there was a difference of $0,1,2,3,4,5$ categories between the two measures. We used $\kappa$ statistic values of $\geqslant 0.61$ to indicate substantial agreement; 0.41-0.60 moderate agreement; and $\leqslant 0.40$ low agreement. ${ }^{34}$

Student's $t$ test was used to estimate the mean difference in birth weight and childhood psychometric intelligence between different measures of occupational social class. In doing so, the indicators of occupational social class were dichotomised into manual (IIIM, IV, and V) and non-manual (I, II, IIINM). Evidence of heterogeneity between these mean differences was assessed graphically and by calculating the Q statistic. ${ }^{35}$ All statistical analyses were computed using Stata software (version 8) (Statacorp, College station, TX).

\section{RESULTS}

Table 1 presents the number of study participants with data for each measure of occupational social class, together with the proportions in the manual and non-manual groups. A high proportion of participants had complete data for early life occupational social class assessed at both the birth of the study participant $(94 \%)$ and when reported in childhood $(92 \%)$.

Table 2 is a cross tabulation of early life social class based on birth records and adult reports. Numbers embolded on the diagonal indicate exact agreement. Numbers above the diagonal signify where the occupation reported in adulthood is of a higher (more advantaged) social class than that obtained for infancy from birth records. Numbers below the diagonal indicate where the occupation reported in adulthood was of a lower (less advantaged) social class than that obtained at birth. There was exact agreement for 54\% of participants between measures of occupational social class at birth and that reported in adulthood. For the remainder, 31\% of adult respondents reported that their father's social class was higher than that recorded at birth and $16 \%$ reported that it was lower (percentages do not exactly total 100 because of rounding). Most disagreement fell into categories immediately adjacent to the diagonal. Levels of exact agreement were slightly higher $(61.4 \%)$ between childhood reports of occupational social class and reports made in middle age (table 3), but the general pattern of agreement was similar to that apparent in table 2 . The weighted $\kappa$ scores for both sets of analyses ranged between 0.47 and 0.56 (both $p<0.001$ ), suggesting a moderate level of agreement.

The somewhat stronger agreement we found between social class during childhood, rather than birth, in relation to adult retrospective reports has at least two explanations that can be tested empirically. Firstly, as adults were asked to retrospectively report their father's occupation when they were aged 12 years, which is closer to childhood prospectively measured childhood social class (at 6-12 years of age) than the birth measurement, it is possible that the somewhat stronger agreement we found between childhood social class and adult retrospective reports represents upward socioeconomic mobility between the 1950s and 1960s among the study members' fathers. To test this hypothesis we examined the level of agreement between the two prospectively collected social class measurements (at birth and 6-12 years of age). There was complete agreement for $67 \%$, whereas for $22 \%$ the birth social class was higher than that measured in childhood and for $11 \%$ the birth social class was lower (full data not shown). On balance, therefore, this does, in fact, indicate downward social mobility.

Secondly, as adult reported childhood occupational social class was based on recall for 12 years of age, it could be that children who were closer to 12 years of age when this information was prospectively collected reported it with greater accuracy. To test this suggestion, we examined the association between adults' recall of childhood social class and prospectively collected data when the latter was stratified

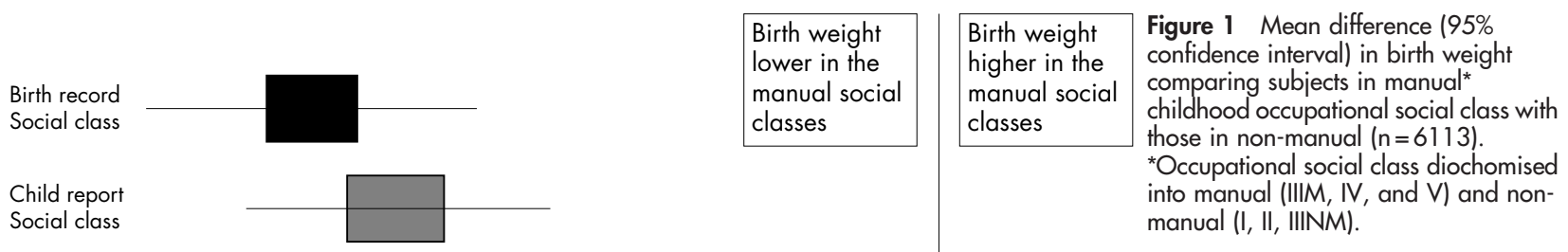

Adult report Social class

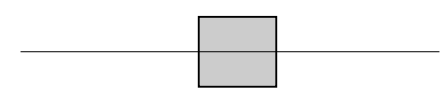
manual (I, II, IIINM).

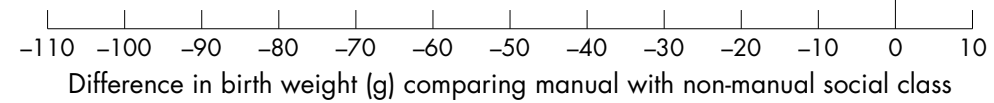

Difference in birth weight $(\mathrm{g})$ comparing manual with non-manual social class 


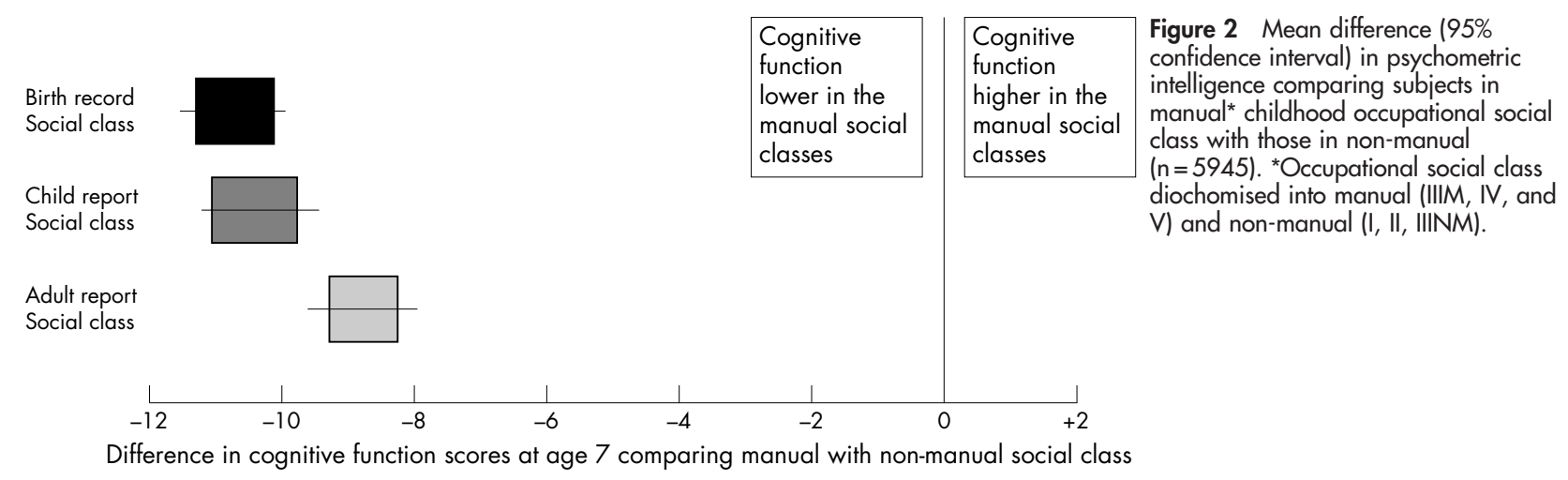

by age at measurement. Levels of agreement were essentially the same whether the child was $<9$ years or $\geqslant 9$ years at the time of the childhood survey.

We examined if there were sex differentials in the accuracy of reporting of these data by stratifying our analyses by sex (data not shown). There was essentially none: the $\kappa$ statistic for social class at birth compared with adult recall was 0.46 (women) and 0.48 (men), while for childhood social class compared with adult recall the results were identical ( $\kappa=0.56$ for men and women). These $\kappa$ statistics, in keeping with those reported in tables 2 and 3 , were significant $(\mathrm{p}<0.001)$.

We compared the difference in mean birth weight (fig 1) and childhood psychometric intelligence (fig 2) between high socioeconomic position and low for each measure of occupational social class. These analyses were conducted on people with complete data on all three measurements of occupational social class and the outcomes $(n=6113$ with birth weight as the outcome, and $n=5945$ with psychometric intelligence as the outcome). The mean (SD) birth weight among women was 3233 (503 g), and among men 3361 $(515 \mathrm{~g})$; the corresponding results for IQ were 107.4 (16.5) and 106.7 (16.3). Negative mean differences-those to the left hand side of the vertical line denoting no effect (that is, zero mean difference)-indicate a lower birth weight or IQ in those from manual compared with non-manual social classes. The point estimates in both figures suggest weaker associations of IQ and birth weight with adult retrospective report of social class in comparison with either prospectively collected early life measurement. While there was no statistical evidence of heterogeneity in the effect of occupational social class on birth weight across the three measures $(p=0.4)$, when IQ was the outcome of interest there was a noticeable weaker association for adult reported childhood social class than for either prospective social class measurement ( $p$ value for heterogeneity $=0.006$ )

\section{DISCUSSION}

In the largest study to date to examine the issue, middle aged adults' recall of early life social class showed moderate agreement with social class data collected prospectively up to five decades earlier, either from birth records or from reports made in childhood. Disagreements were generally ascribed to adults reporting a higher (more favourable) occupational social class to that recorded in early life. To quantify the potential implications of any misclassification we related the occupational social class data to birth weight and childhood intelligence, which have repeatedly been shown to be associated with early life socioeconomic factors. ${ }^{21-23}$ Using each measure of occupational social class resulted in the same conclusion: the lowest levels of birth weight and IQ were found in the most socially disadvantaged groups.

\section{Comparison with other studies}

Our results are in broad agreement with two previous studies addressing the validity of distant recall of childhood socioeconomic position, both of which used data on occupational social class. In the only directly comparable investigation, Berney and Blane ${ }^{19}$ reported an exact match of $66 \%$ between older adults' reports of their father's occupation in their youth and historical data recorded from 50 years earlier. In this study, the sample size was small $(n=57)$ and follow up data were based an intensive interview schedule, an approach that is not practical in large scale, population based studies. However, the similarity in levels of agreement between this and our study, suggest that simple questionnaire inquiries elicit data that are as valid as those obtained from detailed interviews. In the only other study, ${ }^{18}$ the degree of corroboration between adult female twins' reports of fathers' occupation was also high but, as previously indicated, no comparison with historical records was made. In neither of these studies did the investigators attempt to examine the potential implications of any misclassification as we have done.

An alternative assessment of the effect of any misclassification could be provided by using a dataset that holds information on both retrospectively and prospectively collected childhood social class and relating this information to an outcome that has been shown to be socioeconomically patterned, such as CHD. It will be some years before this cohort has accumulated sufficient CHD events to facilitate such an analysis. In the meantime, some evidence for a differential effect of childhood social class reported in adulthood and that prospectively gathered can be found by

\section{What this paper adds}

- Although adult reported childhood socioeconomic position has been related to health outcomes in many studies, very little is known about the validity of such distantly recalled information.

- In this study we found moderate agreement between social class of father recalled in adulthood and that measured prospectively in childhood.

- The relation of childhood IQ and, to a lesser extent, birth weight, was weaker with adult recalled social class than prospectively collected childhood social class data.

- In studies of adult disease aetiology, associations with childhood social class based on adult recall of parental occupation are likely to underestimate any real effects. 
comparing results across studies. In a recent review by Lynch and Davey Smith ${ }^{5}$-necessarily narrative because of the problems of statistically aggregating results from observational studies in a meta-analysis - the authors found that, in studies in which childhood social circumstances were measured prospectively, the relation with CHD was generally stronger than those in which this exposure were recalled in adulthood.

\section{Misclassification of social class}

While misclassification between childhood social class ascertained contemporaneously and recalled in adulthood may be ascribed to inaccuracies in recalling such information from up to five decades earlier, at least three further explanations exist. Firstly, in the original survey dataset made available to us, the occupational data from the schools survey and birth records had been pre-coded to a schema resembling the registrar general's 1950 revision $^{28}$; the verbatim descriptions of occupation, from which these classifications were derived, were not available. In coding parental occupation from data collected in mid-life, the earliest schema available to us for electronic transformation was the 1961 revision. ${ }^{29}$ It is possible, therefore, that some of the disagreement between childhood and adult ascertained childhood is attributable to these coding differences.

Secondly, the periods in which measurement of early life social class was made herein varied across indices. In the follow up questionnaire, carried out when the study participants were middle aged, respondents were asked to focus on the period when they were 12 years of age, while the prospective data were collected at birth (from routine birth records) and when the study participants were between 6 and 12 years of age (reported during the 1962 schools survey). We examined if the age of the school child during participation in the survey modified the level of agreement between reports from this period and those in middle age. On stratifying age at survey into two groups ( $<9$ years and $\geqslant 9$ years), the weighted $\kappa$ statistic was essentially unchanged, suggesting age difference does not explain the misclassification. A third and related point is that there was upwards socioeconomic mobility in the city of Aberdeen between the 1950s-during which the study participants were born and experienced their early childhood-and the 1960s when they would be aged 12 . Two findings mitigate against upwards social mobility as a likely explanation for the lack of agreement. The economic boom in Aberdeen after the discovery of North Sea oil did not occur until the mid-1970s. ${ }^{20}$ Furthermore, our comparison of birth with childhood social classes suggested that there was, in fact, a moderate downward shift in socioeconomic position over this period.

\section{Study strengths and limitations}

The sample size in this study is an order of magnitude higher than others that have examined the same issue; moreover, this is the first to attempt to measure any possible impact of misclassification. While this report therefore represents a unique contribution, various weaknesses should be considered. It is plausible that in study participants whose fathers were particularly socially mobile, recall may be less accurate. We do not, however, have employment histories of these men to enable us to examine this issue. It is also possible that, because of differing cultural contexts, the level of occupational misclassification may vary from one country to another. It may be of value, therefore, to repeat this study in other populations. Additionally, herein, adult reported childhood occupational social class is, by definition, only available for study survivors who responded to a questionnaire survey. However, this reflects the very situation in which adults' recall of childhood circumstances will be used in studies of disease aetiology.

Finally, the response to our mailed questionnaire was moderate $(64 \%)$, with non-responders more likely to be from disadvantaged backgrounds. This response proportion is similar to that in comparable follow up surveys conducted in the $1946^{36}$ and $1958^{37}$ birth cohort studies. When we related reports of childhood social class from the questionnaire to data collected in early life, where disagreement occurred, it tended to be adults placing their fathers' occupation into a higher socioeconomic position compared with their reports in childhood. Had the response proportion been greater, with a higher representation of study participants from poorer childhood social backgrounds, it is plausible therefore that the level of agreement may have been lower and the association with birth weight and childhood intelligence weaker.

\section{Conclusion}

In the largest study to date to examine the issue, there were moderate levels of agreement between prospectively recorded early life social class and adult reports of their father's social class made up to five decades later. Furthermore, where discordance occurred, adults tended to exaggerate their father's status compared with contemporary measures. Associations of the measures of social class with birth weight and childhood intelligence were in the expected directions, and were generally weaker for adult reported measures of childhood social class than for contemporaneous indicators.

We suggest that, where possible, prospectively gathered measures of early life occupational social class should be used in aetiological studies. Where these data are unavailable, associations of childhood social class based on middle aged adults' recall of parental occupation and adult health outcomes are likely to underestimate the real associations.

\section{ACKNOWLEDGEMENTS}

We are grateful to Raymond Illsley for providing us with the data from the Aberdeen child development survey and for his advice about the study. Graeme Ford had a crucial role in identifying individual cohort members and in helping us initiate the process of revitalisation. Doris Campbell, George Davey Smith, Marion Hall, Bianca De Stavola, Susan Morton, David Godden, Di Kuh, Glyn Lewis, and Viveca Östberg collaborated in revitalising the cohort. Margaret Beveridge assisted with the management of the study. We also thank staff at the ISD (Edinburgh), GRO (Scotland), and NHSCR (Southport) for their substantial contributions and John Lemon who undertook the linkage to the AMND. Finally, we are particularly grateful to the study participants who responded to a mailed questionnaire some 40 years after the original survey was completed.

\section{AUTHOR CONTRIBUTIONS}

S Macintyre, G D Batty, and D A Lawlor developed the idea for this paper. D A Lawlor undertook all the statistical analysis. D A Lawlor and G D Batty wrote the first draft of the paper. G D Batty coordinated further revisions to which D A Lawlor, S Macintyre, H Clark, and D A Leon all contributed.

\section{Authors' affiliations \\ G D Batty, S Macintyre, MRC Social and Public Health Sciences Unit, University of Glasgow, Glasgow, UK \\ G D Batty, Department of Psychology, University of Edinburgh, Edinburgh, UK \\ D A Lawlor, Department of Social Medicine, University of Bristol, Bristol, UK \\ H Clark, Dugald Baird Centre, University of Aberdeen, Aberdeen, UK D A Leon, Department of Epidemiology and Population Health, London School of Hygiene and Tropical Medicine, London, UK \\ Funding: the Aberdeen children of the 1950s study was funded as a component project (G0828205) of a Medical Research Council Co- operative Group Life-course and Trans-generational Influences on}


Disease Risk (G9819083). A project on cognition and adult health in the cohort has been financed by the Chief Scientist Office, Scottish Executive Health Department, which currently supports Heather Clark. When work on this manuscript began, G D Batty was supported by a University of Copenhagen Visiting Senior Research Fellowship in Epidemiology; he is now the recipient of a Wellcome Advanced Training Fellowship (071954/Z/03/Z). D A Lawlor is funded by a Department of Health (UK) Career Scientist Award.

Competing interests: none.

Ethical approval: all components of the study revitalisation have been granted various ethical committee permissions, including those from the Multi-centre Research Ethics Committee for Scotland, the Local Research Ethics Committee for Grampian (the region in which Aberdeen falls), and the London School of Hygiene and Tropical Medicine Research Ethics Committee. Tracing of study members using the General Register Office (GRO) (Scotland) was approved by the Privacy Advisory Committee.

\section{REFERENCES}

1 Ben Shlomo Y, Kuh D. A life course approach to chronic disease epidemiology: conceptual models, empirical challenges and interdisciplinary perspectives. Int J Epidemiol 2002;31:285-93.

2 Kuh D, Ben Shlomo Y. A lifecourse approach to chronic disease epidemiology. Oxford: Oxford Medical Publications, 2004.

3 Barker DJP. Mothers, babies and health in later life. Edinburgh: Churchill Livingstone, 1998.

4 Lynch J, Davey Smith G. A life course approach to chronic disease epidemiology. Annu Rev Public Health 2005;26:1-35.

5 Davey Smith G, Lynch J. Socioeconomic differentials. In: Kuh D, Ben Shlomo Y eds. A life course approach to chronic disease epidemiology. Oxford: Oxford Univerity Press, 2004:77-115.

6 Galobardes B, Lynch JW, Davey Smith G. Childhood socioeconomic circumstances and cause-specific mortality in adulthood: systematic review and interpretation. Epidemiol Rev 2004;26:7-21.

7 Heslop P, Davey Smith G, Macleod J, et al. The socioeconomic position of employed women, risk factors and mortality. Soc Sci Med 2001;53:477-85.

8 Lawlor DA, Ebrahim S, Davey Smith G. Association between self-reported childhood socioeconomic position and adult lung function: findings from the British women's heart and health study. Thorax 2004;59:199-203.

9 Blane D, Hart CL, Davey Smith G, et al. Association of cardiovascular disease risk factors with socioeconomic position during childhood and during adulthood. BMJ 1996;313:1434-8.

10 Lawlor DA, Davey Smith G, Patel R, et al. Life-course socioeconomic position, area deprivation, and coronary heart disease: findings from the British women's heart and health study. Am J Public Health 2005;95:91-7.

11 Davey Smith G, Hart C, Blane D, et al. Adverse socioeconomic conditions in childhood and cause specific adult mortality: prospective observational study. BMJ 1998;316:1631-5.

12 Wannamethee SG, Whincup PH, Shaper G, et al. Influence of fathers' social class on cardiovascular disease in middle- aged men. Lancet 1996:348:1259-63.

13 Lawlor DA, Davey Smith G, Kundu D, et al. Those confounded vitamins: what can we learn from the differences between observational versus randomised trial evidence? Lancet 2004;363:1724-7.

14 Lawlor DA, Davey Smith G, Ebrahim S. Socioeconomic position and hormone replacement therapy use: explaining the discrepancy in evidence from observational and randomized controlled trials. Am J Public Health 2004;94:21 49-54.

15 Looker, ed. Accuracy of proxy reports of parental status characteristics. Sociology Education 1989;62:257-76.
16 Lien N, Friestad C, Klepp Kl. Adolescents' proxy reports of parents' socioeconomic status: How valid are they? J Epidemiol Community Health 2001;55:731-7.

17 Bourbonnais $\mathbf{R}$, Meyer F, Theriault G. Validity of self reported work history. $\mathrm{Br}$ J Ind Med 1988:45:29-32.

18 Krieger N, Okamoto A, Selby JV. Adult female twins' recall of childhood social class and father's education: a validation study for public health research. Am J Epidemiol 1998;147:704-8.

19 Berney LR, Blane DB. Collecting retrospective data: accuracy of recall after 50 years judged against historical records. Soc Sci Med 1997;45:1519-25

20 Batty GD, Morton SMB, Campbell D, et al. The Aberdeen children of the 1950s cohort study: background, methods and follow-up information on a new resource for the study of life course and intergenerational influences on health. Paediatr Perinat Epidemiol 2004;18:221-39.

21 Batty GD, Leon DA. Socio-economic position and coronary heart disease risk factors in children and young people. Evidence from UK epidemiological studies. Eur J Public Health 2002; 12:263-72.

22 Macfarlane A, Mugford M. Birth counts. Statistics of pregnancy and childbirth, Vol 1. London: HMSO, 2000.

23 Neisser U, Boodoo G, Bouchard Jnr T, et al. Intelligence: knowns and unknowns. Am Psychol 1996;51:77-101.

24 Birch HG, Richardson SA, Baird D, et al. Mental subnormality in the community: a clinical and epidemiologic study. Baltimore: Williams and Wilkins, 1970.

25 Illsley R, Wilson F. Longitudinal studies in Aberdeen, Scotland. C. The Aberdeen child development survey, In, Mednick S, Baert A, Bachmann B, eds. Prospective longitudinal research. An empirical basis for the primary prevention of psychosocial disorders. Oxford: Oxford Univerity Press, 1981:66-8.

26 Batty GD, Clark H, Morton SMB, et al. Intelligence in childhood and mortality, migration, questionnaire response rate, and self-reported morbidity and risk factor levels in adulthood - preliminary findings from the Aberdeen 'children of the 1950s' study. J Epidemiol Community Health 2002;56(suppl II):A1

27 Samphier M, Thompson B. Longitudinal studies in Aberdeen, Scotland. B. The Aberdeen Maternity and neonatal data bank. In, Mednick S, Baert A Bachmann B, eds. Prospective longitudinal research. An empirical basis for the primary prevention of psychosocial disorders. Oxford: Oxford University Press, 1981:61-5.

28 General Register Office. Classifications of occupations 1950. London: HMSO, 1951.

29 Registrar General. The registrar general's decennial supplement, England and Wales 1961, occupational mortality tables. London: HMSO, 1971

30 Elias P, Halstead K, Prandy K. Computer assisted standard occupational coding. London: HMSO, 1993.

31 Morton SMB, Leon DA, De Stavola BL. Perinatal and postnatal predictors of childhood IQ. J Epidemiol Community Health 2001;55:A24.

32 Batty GD, Leon D, Rahi J. Relation of birth weight, gestational age, paternal socio-economic position, and early childhood height to prevalent reduced distant visual acuity in children born in Aberdeen in the 1950s. J Epidemio Community Health 2001;55:A24.

33 Batty GD, Morton SMB, Maclntyre S, et al. Size at birth and cardiovascular disease mortality: evidence from the Aberdeen children of the 1950s study. Pediatr Res 2003;53(suppl):21A.

34 Landis JR, Koch GG. The measurement of observer agreement for categorical data. Biometrics 1977;33:159-74.

35 Sterne J, Bradburn M, Egger M. Meta-analysis in STATA. In: Egger M, Davey Smith G, Altman D, eds. Systematic reviews in health care: meta-analysis in context. London: BMJ Books, 2001.

36 Wadsworth ME, Butterworth SL, Hardy RJ, et al. The life course prospective design: an example of benefits and problems associated with study longevity. Soc Sci Med 2003;57:2193-205.

37 Parsons TJ, Manor O, Power C. Changes in diet and physical activity in the 1990s in a large British sample (1958 birth cohort). Eur J Clin Nutr 2004;59:49-56. 